\title{
Spoken and Written Story Production Ability of School-Aged Children with High-Functioning Autism Spectrum Disorders
}

\author{
Hyun Jun Cho ${ }^{a}$, Hee Ran Lee ${ }^{b}$ \\ ${ }^{a}$ Good Gang-An Hospital, Busan, Korea \\ ${ }^{b}$ Department of Speech and Hearing Therapy, Catholic University of Pusan, Busan, Korea
}

\author{
Correspondence: Hee Ran Lee, PhD \\ Department of Speech and Hearing Therapy, \\ Catholic University of Pusan, 57 Oryundae-ro, \\ Geumjeong-gu, Busan 46252, Korea \\ Tel: +82-51-510-0841 \\ Fax: +82-51-510-0848 \\ E-mail: hrlee@cup.ac.kr
}

Received: January 3, 2017

Revised: February 22, 2017

Accepted: March 3, 2017

This paper is based on the master's thesis of the first author.

\begin{abstract}
Objectives: The present study examined story production ability, which is necessary for educational success, by using speaking and writing methods to investigate the narrative abilities of school-aged children with high-functioning autism spectrum disorders (HFA). Methods: Fifteen children with HFA and 15 receptive vocabulary ability-matched, typically developing children (TD) participated in this study. A story "Frog, Where Are You," was used to test spoken and written story production ability. Results: First, HFA group showed significantly lower performance than the TD group on the speaking and writing tasks in the number of cohesive devices used, total amount of story grammar used, number of full episodes, MLC-w (mean length of communication for word), and NDW (number of different words). However, there was no significant difference between the two groups in terms of the total C-units. Second, the two groups showed significantly higher performance in speaking than that of writing in the number of cohesive devices used, total amount of story grammar used, total C-units, and NDW. However, there was no significant difference between production methods in MLC-w and the number of full episodes. Conclusion: Children with HFA have difficulties with syntactic complexity and vocabulary diversity including the ability to arrange a story and to use cohesive devices and linguistic markers, despite similar length of C-units in story production. It is important to identify their story production ability not only through speaking, but by also considering their writing.
\end{abstract}

Keywords: High-functioning autism spectrum disorder, Story, School-aged children, Speaking, Writing
아동이 초등학교에 입학하게 되면 교과과정을 통해 접하는 다 양한 지식들을 학습하기 위해 말하기에 더해 읽기와 쓰기라는 문 해력을 수단으로 의미론과 통사론, 그리고 담화 능력에서 발달적 성취를 이뤄내야 한다. 따라서 이야기, 설명, 설득 등 학령 전기와는 다른 다양한 담화 상황에서 여러 가지 방식의 의사소통 능력을 발 달시켜 가야 한다. 특히, 학업 성취를 위해 무엇보다 강조되는 담화 능력의 하나인 이야기를 이해하기 위해서는 개인이 가진 배경 지 식, 사건의 일반적인 순서, 주인공의 역할 그리고 전체적인 배경을 바라보는 능력 등에 대한 인식과 더불어, 사건이 일어나는 인과관 계를 파악할 수 있어야 하며, 이야기를 해결하기 위해 주인공이 시
도해야 하는 일련의 행동들을 파악할 수 있는 문제해결 전략 역시 요구된다(Owens, 2014).

아동이 이야기를 정확하게 이해한 후 표현하는지를 분석하기 위 해서는 이야기의 전체적인 사건을 일련의 순서로 전개하며 표현하 는지에 관련된 이야기문법과 더불어, 구성력 있고 탄탄한 이야기를 산출하기 위해 상황에 적절한 어휘를 선택하고 적절한 문장을 산 출하는지를 살펴볼 수 있어야 한다. 또한 이야기문법을 갖추고 이 야기를 전달할 때 보다 구성력 있는 이야기를 만들기 위해 사용하 는 담화적 결속장치(cohesive devices)는 단어 간에서나 단어와 문 장, 그리고 문장과 문장을 의미적으로 결속시키는 총체적인 언어 
장치라고 할수 있다(Pae \& Lee, 1996).

본 연구에서 분석하고자 하는 말하기와 쓰기는 자신의 의도를 전달하거나 상대방을 이해시키기 위한 목적의 표현 양식이라는 공 통점이 있다. 하지만 말하려는 내용과 문법지식 등을 고려하여 언 어기관들의 빠른 처리 압력 아래 산출이 이뤄지는 말하기와는 대 조적으로, 쓰기는 보다 계획적이며 모니터링이 가능한 특징이 있다 (Strömqvist, Nordqvist, \& Wengelin, 2004). 또한 쓰기는 글을 쓰는 사람의 생각과 지식이 확연히 드러내는 표현 양식이므로, 생각을 만들어내기, 조직화, 계획, 수정, 모니터, 그리고 스스로 피드백 주기 가 가능한 복잡한 인지과정의 총합이라고 할 수 있다(Scott, 1999).

하지만, 언어장애 아동에게 쓰기는 말하기만큼이나 어려운 소통 양식 가운데 하나이다. 쓰기 역시 하나의 사회적 소통 행위이므로 말하기에서 듣는 이를 고려하는 것과 마찬가지로 읽는 이를 고려해 야 한다. 즉, 쓰기가 이뤄지는 상황에 읽는 이가 함께 하지 않는 경 우가 많으므로, 쓰기를 위해서는 말하기보다 계획과 집행을 위해 더 많은 시간을 할애하기도 한다. 말로 하는 소통과 시각적 소통 사 이에는 처리 과정의 일부분이 겹치기도 하지만, 쓰기는 인지 능력 과 집행 기능, 기억과 같은 다양한 인지과정에 덧붙여 보다 탈맥락 화된 정보 처리가 요구되는 상위언어적 기술을 필요로 한다. 의사 소통 방식으로써 말하기와 쓰기는 유사한 점이 많지만 특징적인 차이점을 보인다. 첫째, 말하기는 시간적으로 이어지는 말소리로 구 성되는 반면 쓰기는 이차원적 공간에 표현되는 문자 기호로 구성 된다. 둘째, 쓰기는 말하기에 비해 개인적인 생각이나 사고를 확장 하고 명료화하는 수단이 될 수 있다. 셋째, 말하기와 쓰기는 어휘 수준에서도 차이를 보이는데, 어휘다양도(type-token ratios, TTRs) 와 어휘 밀도(lexical density)에서 유의미한 차이를 나타낸다고 한 다(Kamhi, \& Catts, 2011).

자폐범주성장애(autism spectrum disorder, ASD) 아동은 의사 소통과 사회적 상호작용에 결함이 있고, 상동행동이나 제한적인 관심을 보인다(American Psychiatric Association [APA], 2013). 많 은 $\mathrm{ASD}$ 아동들이 지적 결함을 동반하지만, 비교적 지적 수준이 정 상 범주에 속하지만 $\mathrm{ASD}$ 의 핵심 특징을 보이는 경우, 임상적 분류를 위해 고기능 자폐범주성장애(high-functioning autism spectrum disorders, 이하 고기능 ASD)라는 진단명이 사용되고 있다. 최근 개 정된 DSM-5 (APA, 2013)는 ASD 아동의 심각도(severity)에 대해 지원이 필요한 1단계, 상당한 지원이 필요한 2단계, 매우 상당한 지 원이 필요한 3 단계로만 분류하고 있으므로, 1 단계에 속한 아동들 의 경우 고기능 $\mathrm{ASD}$ 로 분류될 가능성이 높다고 할 수 있다.

$\mathrm{ASD}$ 아동의 이야기 산출 능력에 관한 선행연구들에 따르면, 인 지와 언어 능력이 유사한 또래와 비교할 때 산출성(productivity)이
나 어휘다양도, 의미론, 구문 복잡성에서 유사한 수준이라는 연구 결과들이 있는 반면(Diehl, Bennetto, \& Young, 2006; Losh \& Capps, 2003; Norbury \& Bishop, 2003), ASD 아동들이 통사적으로 덜 복 잡한 문장을 사용하거나 의미론적 결함이 두드러진다는 연구들도 이어지고 있다(King, Dockrell, \& Stuart, 2014; Norbury, Gemmell, \& Paul, 2014). 이러한 결과는 이야기 과제의 종류나 이야기 산출을 유도하는 방식에 따른 차이일 수도 있어 해석에 유의할 필요가 있 지만, 무엇보다 연구자들이 동의하는 $\mathrm{ASD}$ 아동의 이야기 산출 결 함은 이야기의 사건을 연결하는 데 필요한 구성(plot structure), 인 과관계의 연결, 그리고 다양한 언어적 장치들로 표현해야 하는 결 속장치 즉, 응집성(coherent)의 부족이었다(Barnes \& Baron-Cohen, 2012; Diehl et al., 2006; King et al., 2014; McCabe, Hillier, \& Shapiro, 2013). 이야기 과제 수행에서 드러나는 응집성의 부족이나 잘못된 사용은 고기능 $\mathrm{ASD}$ 아동에게서는 더욱 두드러지는데, 듣 는 이의 관점에서 정보를 조직화하는 것과 관련된 마음 이론 결함 에 기인하는 것으로 해석되고 있기도 하다(Colle, Baron-Cohen, Wheelwright, \& van der Lely, 2008; Hilvert, Davidson, \& Gámez, 2016).

일반 $\mathrm{ASD}$ 아동과 달리 고기능 $\mathrm{ASD}$ 아동은 언어능력에서의 지 체가 두드러지지는 않지만 저장된 의미를 효율적으로 처리하는 데 어려움을 보이며, 구문론적 지식 수준에 미치지 못하는 정도의 언 어를 사용하거나 기능적 측면에 결함이 있다(Renner, Klinger, \& Klinger, 2000; Tager-Flusberg, 2004). 또한, 자신의 생각이나 표현 하고자 하는 내용을 구성하는 능력이 부족하며, 인물의 감정을 이 해하고 사회적 경험을 이야기에 적용하는 능력에 어려움을 보인다 (Landa \& Goldberg, 2005; Tager-Flusberg, 2000; Tager-Flusberg, Paul, \& Lord, 1997). 특히, 쓰기 과제의 경우 고기능 ASD 인들은 비 언어적 지능이 높았음에도 공식 쓰기검사에서 매우 낮은 점수를 받거나(Brown, 2013), 쓰기 과제 수행 시 장애 유형의 스펙트럼만 큼이나 변이가 매우 두드러진다고 한다(Foley-Nicpon, Assouline, \& Stinson, 2012; Mayes \& Calhoun, 2003, 2008). 이러한 특성은 성 인기에까지 이어져 주제 유지나 변경의 어려움 그리고 응집성 부족 으로 이어진다(Brown \& Klein, 2011).

연구에 따르면 평균 또는 그 이상의 지적 수준을 가진 고기능 $\mathrm{ASD}$ 성인일지라도 $34 \%-47 \%$ 만이 안정적인 직업에 종사하지만 임 금이나 직업 환경은 매우 열악한 수준이라고 한다(Howlin, 2003; Howlin, Goode, Hutton, \& Rutter, 2004). 따라서 초기 학령기부터 이들의 장애특성과 관련한 학업수행에서의 강점과 약점을 파악하 여 전생애적 지원으로 이어져야 할 것이다. 특히, 이야기는 사고의 방식, 의사소통, 현실성 공유와 더불어 고기능 ASD 아동의 결함을 
규정짓는 핵심이므로(Baixauli, Colomer, Roselló, \& Miranda, 2016), 이러한 특징들이 두드러지게 발달하며 사회인지 형성에 기여하게 되는 학령기에 이들 고기능 ASD 아동의 이야기 쓰기와 말하기의 발달적 특징에 대한 연구 자료들이 보다 다양하게 축적될 필요가 있을 것이다.

이상의 연구 결과들을 살펴볼 때, 학령기 고기능 ASD 아동의 언 어 및 담화 특성을 살펴보기 위해서는 말하기뿐만 아니라 쓰기라 는 표현 양식의 발달을 구조화된 이야기과제를 통해 비교해 볼 필 요가 있음을 확인할 수 있었다. 특히 이야기과제는 구문 산출과 의 미 관련 특성을 말하기와 더불어 읽기와 쓰기 과제를 통해 구체적 으로 평가하는 측정치들을 제공해 줄 수 있으므로 국내에서도 여 러 선행연구들에서도 활용되고 있다(Heo, Kwag, \& Lee, 2011; Kim, 2015; Lee \& Jung, 2013). 또한 학령기 아동의 설명담화 말하기와 쓰 기 발달을 구문, 의미, 결속장치를 중심으로 살펴본 Lee와Jung (2013) 에 따르면, 쓰기에서는 고학년에 이르러 구문복잡성의 학년별 발달 적 차이가 드러나지 않았으므로, 가능한 말하기와 쓰기 발달의 차 이를 저학년에서 살펴보는 것이 적절할 것이다.

따라서 본 연구에서는 말하기와 쓰기라는 언어 표현 양식에 따 른 학령기 고기능 $\mathrm{ASD}$ 아동의 이야기 산출 특성을, 이들과 수용어 휘력을 일치시킨 일반 아동의 수행과 비교하여 분석하고자 하였다. 고기능 $\mathrm{ASD}$ 아동들의 경우 특히 담화적인 면에서 많은 어려움을 보이므로, 이야기 다시 말하기와 다시 쓰기 과제의 수행 차이를 비 교함으로써 이들 아동들의 언어 표현 양식을 이해하여 평가와 중 재에 적용할 수 있을 것이기 때문이다.

\section{연구 방법}

\section{연구 대상}

본 연구는 부산광역시에 거주하는 초등 저학년(1-3학년) 고기능 $\mathrm{ASD}$ 아동 15 명, 그리고 이들과 수용어휘력을 일치시킨 일반 아동 15 명을 대상으로 하였다. 고기능 ASD 아동은 (1) 소아정신과 또는 신경정신과에서 DSM-IV (APA, 2000)와 DSM-5 (APA, 2013)의 진 단기준에 따라 $\mathrm{ASD}$ 로 진단받거나 의심된다고 보고된 아동 중에 서, (2) 아동기 자폐증 평정척도(CARS; Kim \& Park, 1996)에서 30 점 이상 점수를 획득하고, (3) 한국판 카우프만 아동용 지능검사 (K-ABC; Moon \& Byun, 2009) 결과, 동작성 지능이 70 이상이며, (4) 다른 지체장애와 감각장애를 동반하지 않은 아동으로 선정하 였다. 또한 일반 아동 집단과의 어휘 이해력 비교를 위해 수용-표현 어휘력검사(REVT; Kim, Hong, Kim, Jang \& Lee, 2009)의 수용어 휘력검사를 실시하였다.
일반 아동은 (1) 소아정신과 또는 신경정신과에서 어떠한 임상적 진단도 받지 않은 아동이며, (2) REVT (Kim et al., 2009)의 수용어 휘력 결과 -1 SD 이상이고, (3) 언어문제해결력검사(Pae, Lim, \& Lee, 2000)에서 -1 SD 이상이며, (4) 부모나 학급 담임 교사로부터 신체, 운동, 정서발달에 문제가 없다고 보고된 아동으로 하였다. 또 한, (5) 고기능 ASD 아동의 REVT (Kim et al., 2009) 수용어휘력 등 가연령이 동일 점수대에 속하는 아동으로 선정하였으며, 자발적인 사건 묘사를 3 문장 이상을 말하고 쓸 수 있는 아동들이었다.

고기능 $\mathrm{ASD}$ 아동 집단의 생활연령 평균은 97 개월이었으며, 학 년은 1학년 7명, 2학년 1명, 3학년 7명이었다. 언어연령 일치 아동 집 단의 생활연령은 평균 93 개월이었으며, 1 학년 5명, 2 학년 8 명, 3 학년 2 명이었다.

연구 대상자들의 특성과각 검사점수의 결과를 Table 1에 제시하 였다.

\section{연구 도구}

본 연구에서는 학령기 아동의 이야기 이해 및 산출과 관련된 여 러 연구들에서 사용된 “Frog, Where Are You?”(Mayer, 1969)를 이 용하였다. “Frog, Where Are You?”는 Stein과 Glenn (1979)이 제시 한 기준에 따라 완전한 일화의 구성을 갖춘 5 개의 에피소드로 구성 되어 있고 각각의 에피소드는 5-6개의 문장으로 구성된다.

\section{연구 절차}

대상자 선정을 위해 학교와 학원 등을 통해 부모의 동의를 구하 는 절차를 진행하였으며, 검사를 원하는 아동의 집 또는 학교, 치료 실 등에서 아동과 개별적으로 검사를 진행하였다. 먼저 기초검사 인 동작성 지능검사, REVT 중 수용어휘력검사, 언어문제해결력검 사를 실시하였다. 검사간에는 약 2-3분간의 적당한 휴식 시간을 가 겼다. 기초검사가 끝난 후, 연구자는 휴식 시간에 대상자와 간단한 질문과 대화를 하여 아동의 긴장을 줄여 주었고, 이후 검사절차에

Table 1. Participants' characteristics

\begin{tabular}{lcc}
\hline & Children with HFA $(\mathrm{N}=15)$ & Normal children $(\mathrm{N}=15)$ \\
\hline Age $(\mathrm{mo})$ & $97.67(12.33)$ & $93.47(8.18)$ \\
REVT-R & $91.47(16.02)$ & $90.00(17.10)$ \\
TOPS & - & $38.33(7.14)$ \\
CARS & $31.30(1.08)$ & - \\
IO & $76.73(3.15)$ & - \\
\hline
\end{tabular}

Values are presented as mean (SD).

HFA=high-functioning autism spectrum disorder; REVT-R=Receptive and Expressive Vocabulary Test-Receptive (Kim, Hong, Kim, Jang \& Lee, 2009); TOPS= Test of Problem Solving (Pae, Lim, \& Lee, 2000); CARS=Childhood Autism Rating Scale (Kim \& Park, 1996). 
대해 설명해 주었다. 검사 중 이루어지는 모든 절차에 대해 녹음되 고 있음을 알려 주었고, 검사절차에 대하여 궁금하거나 질문할 사 항이 있는지 확인 후 본 검사를 실시하였다.

먼저 아동에게 "Frog, Where Are You?" 그림을 제시한 후, 연구 자는 “지금부터 재미있는 이야기를 들려줄게요. 그림책을 잘 보면 서 선생님 이야기를 들어 보세요.” 라고 말한 후 그림을 처음부터 하나씩 보여주며 이야기를 들려주었다. 이후, 처음부터 그림을 보 여주며 “OO이가 들었던 이야기를 선생님께 다시 한번 들려줄래?” 라고 말하고 아동의 말을 녹음하였다.

아동의 이야기 다시 말하기가 끝난 후에는, 그림을 처음부터 다 시 보여주며 "OO아! 이번에는 그림을 다시 보면서 이야기 내용을 글로 한번 써볼까?” 라고 말해준 뒤 아동에게 종이와 펜, 지우개를 주며 글로 작성하게 하였다. 이야기 말하기와 쓰기 순서는 교차균 형화(cross-balancing)하여 실시하였고, 아동이 산출한 발화는 모 두 녹음하여 3 일 이내에 전사하여 분석하였다.

\section{자료 분석}

본 연구에서는 고기능 $\mathrm{ASD}$ 아동이 이야기 산출 과제에서 이야 기 구성과 관련하여 이야기문법 결함(Norbury et al., 2014)과 담화 응집성(coherence)의 결함이 두드러진다(Diehl et al., 2006; Heilmann, Miller, Nockerts, \& Dunaway, 2010; Norbury \& Bishop, 2003) 는 선행연구의 근거를 바탕으로 말하기와 쓰기 과제 모두에서 이야 기문법 수와 완전한 일화 수, 그리고 담화적 결속장치를 측정치로 분석하고자 하였다. 또한 산출성(productivity)에 제한이 있다는 선 행연구(Mäkinen et al., 2014; Norbury et al., 2014)를 바탕으로 미 시 구조(microstructure) 가운데 C-unit 내 서로 다른 낱말 수와 평 균낱말길이를 측정치로 선정하였다.

\section{이야기 구성력 - 이야기문법과 완전한 일화 수}

이야기 구성력과 관련하여 Kwon, Pae와 Jin (2009)의 이야기 평 가(KONA) 분류 범주에 따라 배경, 내적 반응, 계기 사건, 시도, 결 과로 이야기문법(story grammars)을 분석하였다. 완전한 일화 수 (full episodes)는 Stein과 Glenn (1979)에 따라 등장인물이 모두 등 장하고 계기 사건, 시도, 결과를 포함한 하나의 에피소드를 구성한 것으로 정의하여 분석하였다. 이 과정에서 이야기 구성력 분석 중 이야기 주요 내용과 관련이 없는 부분에 대해서는 채점에서 제외 하였다.

담화적 결속장치(cohesive device)

담화적 결속장치는 Kwon (2006) 그리고 Choi, Kim과 Yun (2013)
을 참조하여, 연결어미, 접속사, 보조사, 지시 및 대용, 어휘의 5 가지 유형으로 분석하였다. 본 연구의 분석 측정치인 담화적 결속장치 에 대한 조작적 정의는 Appendix 1에 제시하였다.

\section{의미와 평균낱말길이(NDW, MLC-w)}

전체 이야기 발화를 Kwon (2010)을 참조하여 의사소통 단위(communication unit, C-unit)를 분류하여 분석하였으며, 의미와 관련 된 분석을 위해 전체 C-unit에서 사용한 다른 낱말 수(number of different word, NDW)를 분석하였다. 또한 C-unit 당 평균낱말길 이(MLC-w = 총 낱말 수/총 C-unit 수)를 분석하였으며, 이 과정에 서 낱말의 정의는 Lee (2015)를 참조하여 품사단위로 분석하였다. 그러나 이야기 산출 과정에서 나타나는 어휘, 문법, 구문의 오류에 대해서는 분석에 포함시키지 않았다. 평균낱말길이는 학령기 아동 의 내러티브 쓰기 분석에서 학년에 따른 발달적 변화를 확인할 수 있는 측정치로 알려져 있다(Ahn \& Kim, 2010; Lee \& Jung, 2013).

\section{신뢰도}

전체 분석은 본 연구의 주 연구자가 실시하였으며, 전사 신뢰도 와 분석 신뢰도를 검증하기 위해 3 명의 평가자에게 분석지침을 설 명해주고 분석 일치도를 산출하였다. 평가자들은 (1) 언어재활사 2 급 자격증을 소지하고 있으며, (2) 2년 이상 언어치료기관에 재직하 고 있는 언어재활사로 선정하였다. 본 연구의 분석을 위해 녹음된 30 명 아동의 자료 중 $20 \%$ 인 6 명에 대한 전사자 간 전사신뢰도는 $97.86 \%$ 였으며, 분석자 간 신뢰도는 $89.78 \%$ 였다.

\section{통계 처리}

집단(고기능 ASD 집단, 일반 아동 집단)과 산출 방식(말하기, 쓰 기)에 따라 이야기 구성력, 담화적 결속장치 총 사용수, 그리고 다 른 낱말 수와 평균낱말길이에 차이가 있는지 살펴보기 위해 반복 측정 이원분산분석(repeated two-way ANOVA)을 PASW statistics 18.0 을 이용해 실시하였다.

\section{연구 결과}

\section{산출 방식에 따른 고기능 ASD 아동과 일반 아동의 이야기 구성력}

고기능 ASD 아동과 일반 아동 간 이야기 말하기와 쓰기 과제에 서 분석한 이야기문법 총 수와 완전한 일화 수에 대한 기술 통계 결 과는 Table 2와같다.

고기능 ASD 집단은 일반 아동 집단보다 말하기와 쓰기 모두에 
Hyun Jun Cho, et al. • Story Production Ability of School-aged Children with High-functioning ASD

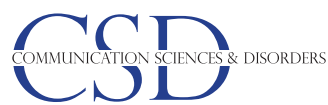

Table 2. Total story grammar and full episodes according to the group

\begin{tabular}{lcc}
\hline & HFA $(\mathrm{N}=15)$ & TD $(\mathrm{N}=15)$ \\
\hline Story grammar & & \\
Speaking & $6.33(4.45)$ & $9.80(2.90)$ \\
Writing & $5.40(4.27)$ & $7.60(2.69)$ \\
Full episodes & & \\
Speaking & $.27(.46)$ & $.73(.59)$ \\
Writing & $.33(.49)$ & $.80(.41)$ \\
\hline
\end{tabular}

Values are presented as mean (SD)

$\mathrm{HFA}=$ high-functioning autism spectrum disorder; $\mathrm{TD}=$ typically developing.

Table 3. Cohesive devices according to the group

\begin{tabular}{lll}
\hline & HFA $(N=15)$ & TD $(N=15)$ \\
\hline Speaking & $22.53(14.55)$ & $31.80(15.59)$ \\
Writing & $11.00(7.85)$ & $19.93(8.56)$ \\
\hline
\end{tabular}

Values are presented as mean (SD).

HFA= high-functioning autism spectrum disorder; TD = typically developing.

서 더 적은 이야기문법 총 수를 산출하였으며, 두 집단 모두 쓰기보 다 말하기에서 더 높은 수행을 보였다. 분산분석 실시 결과에서도 집단에 따른 유의미한 차이가 있었으며 $\left(F_{(1,28)}=5.831, p<.05\right)$, 산출 방식에 따라서도 유의미한 차이가 나타났지만 $\left(F_{(1,28)}=5.902, p<.05\right)$, 상호작용 효과는 나타나지 않았다.

완전한 일화 수를 분석한 결과, 고기능 ASD 아동 집단이 말하기 와 쓰기 모두에서 일반 아동 집단보다 수행이 저조하였지만, 이야 기문법의 총 수와는 달리 두 집단 모두 말하기가 아닌 쓰기에서 더 많은 완전한 일화수를 산출하였다. 분산 분석 결과, 집단에 따라서 는 통계적으로 유의미한 차이가 있었지만 $\left(F_{(1,28)}=8.575, p<.05\right)$, 산 출 방식에 따라서는 유의미한 차이가 나타나지는 않았다.

\section{산출 방식에 따른 담화적 결속장치 사용}

두 집단의 담화적 결속장치 사용 수의 차이에 대한 기술 통계 결 과를 Table 3 에 제시하였다. 고기능 ASD 아동들은 일반 아동들보 다 말하기와 쓰기 모두에서 더 적은 담화적 결속장치를 산출하였으 며, 두 집단 모두 쓰기보다 말하기에서 수행이 더 높았다. 분산분석 을 실시한 결과, 집단 $\left(F_{(1,28)}=5.453, p<.05\right)$ 과산출 방식 $\left(F_{(1,28)}=30.982\right.$, $p<.001)$ 모두에서 통계적으로 유의미한 차이가 있었지만, 상호작 용효과는 나타나지 않았다.

\section{산출 방식에 따른 다른 낱말 수와 평균낱말길이}

고기능 ASD 아동과 일반 아동 간의 서로 다른 낱말 수(NDW), 총 C-unit 수, 그리고 평균낱말길이(MLC-w)를 분석한 기술통계 결 과는 Table 4 와 같다.
Table 4. NDW, total C-units, and MLC-w according to the group

\begin{tabular}{lll}
\hline & HFA $(\mathrm{N}=15)$ & $\mathrm{TD}(\mathrm{N}=15)$ \\
\hline NDW & & \\
Speaking & $54.53(14.30)$ & $65.33(14.30)$ \\
Writing & $41.07(11.37)$ & $57.53(19.21)$ \\
Total C-units & & \\
Speaking & $29.73(8.41)$ & $30.20(8.09)$ \\
Writing & $21.07(8.79)$ & $23.73(8.19)$ \\
MLC-w & & \\
Speaking & $3.85(.78)$ & $4.79(1.02)$ \\
Writing & $3.68(.56)$ & $4.67(.96)$ \\
\hline
\end{tabular}

Values are presented as mean (SD).

HFA= high-functioning autism spectrum disorder; $T D$ = typically developing; $N D W=$ number of different words; MLC-W= mean length of communication for word.

고기능 ASD 아동은 일반 아동보다 다른 낱말 수 사용에서 유의 미하게 수행이 저조하였으며 $\left(F_{(1,28)}=6.520, p<.05\right)$, 두 집단 모두 쓰 기보다 말하기에서 다른 낱말 수 사용이 더 많았지만 $\left(F_{(1,28)}=12.690\right.$, $p<.01)$, 집단과산출방식에 따른 상호작용 효과는 나타나지 않았다.

총 C-unit 수 산출에서도 고기능 ASD 아동은 일반 아동에 비해 수행이 저조하였지만, 이러한 차이가 통계적으로 유의미하지는 않 았다. 두 집단 모두 쓰기보다는 말하기에서 더 많은 총 C-unit 수를 산출하였는데, 이는 통계적으로도 유의미하였으며 $\left(F_{(1,28)}=37.425\right.$, $p<.001)$, 집단과 산출 방식에 따른 상호작용 효과는 나타나지 않 았다.

평균낱말길이 사용에서도 고기능 $\mathrm{ASD}$ 집단은 유의미하게 수행 이 더 저조하였지만 $\left(F_{(1,28)}=14.060, p<.01\right)$, 산출 방식에 따라서는 유의미한 차이가 나타나지 않았으며 집단과 산출 방식에 따른 상호 작용 효과도 나타나지 않았다.

\section{논의 및 결론}

본 연구에서는 초등학교 저학년(1-3학년) 고기능 ASD 아동, 그 리고 이들과 수용어휘력을 일치시킨 일반 아동의 말하기와 쓰기 특성을 이야기 과제를 통해 비교하였다. 이야기를 들려준 뒤 말하 기와 쓰기로 산출하게 하였으며, 이야기문법 총 수와 완전한 일화 수 같은 이야기 구성력과 담화적 결속장치, 그리고 C-unit 수를 분 석하여 C-unit당 다른 낱말 수(NDW)와 평균낱말길이(MLC-w)를 분석하였다.

연구 결과, 첫째, 이야기문법 총 수와 완전한 일화 수를 분석했을 때, 고기능 $\mathrm{ASD}$ 아동은 일반 아동보다 유의미하게 말하기 과제 수 행이 저조하였다. 특히, 고기능 ASD 아동은 일반 아동보다 이야기 를 일련의 순서로 보지 않고 그림의 한 곳에 국한해 일 부분에 대해 서만 말하는 가 하면, 계기사건, 시도, 결과의 이야기문법 수가 적었 
던 대신 배경을 좀 더 많이 말함으로써 이야기 구성력에서의 취약 성을 드러냈다. 이는 “Frog, Where Are You?”를 이용해 고기능 ASD 아동의 이야기문법 말하기를 분석했을 때, 일반 아동보다 이야기 구성능력이 유의미하게 낮았다는 Losh와 Capps (2003)의 연구 결 과와도 일치한다. 배경 자체는 사건의 흐름이나 연결에 관한 인과 관계 추론이 비교적 요구되지 않는 요소라고 할 수 있다. 따라서 주 제를 조직화하여 유지하거나 적절하게 변경하기, 상황 정보를 통해 추론하기 등에 어려움이 있는 고기능 ASD 아동의 경우(Landa, 2000; Tager-Flusberg et al., 1997), 이처럼 다른 이야기문법 요소에 비해 배경을 좀 더 많이 말하는 특성이 나타났다고 해석할 수 있을 것이다.

또한 산출 방식과 관련해, 두 집단 모두 말하기에 비하여 쓰기에 서 이야기문법을 산출하는 데 어려움이 나타났는데 이는 쓰기에 요구되는 소근육의 협응, 시지각, 한글에 대한 지식 등의 과제들이 아동에게 부담이 되어(Youn, Kim, \& Ham, 2007), 말하기로 산출 할 수 있었던 이야기라도 쓰기에서는 생략되거나, 다른 의미로 바 뀌어 쓰여짐으로써 이야기 구성 요소에 포함되지 못한 것으로 해 석할 수 있었다. 특히, $\mathrm{ASD}$ 아동은 읽는 이를 고려하는 전제 능력 의 제약이나 어휘 선택의 결함, 주제의 탐색과 결정의 어려움뿐 아 니라, 보속증과 운동 근육의 미숙, 그리고 입력자극의 비정상적인 수용으로 인해 쓰기에 어려움을 받기도 한다(Mayes \& Calhoun, 2003). 따라서 이러한 ASD 아동의 고유 특성 역시 말하기와 더불 어쓰기 과제에서의 어려움으로 이어진 것으로 보인다.

하지만, 두 집단 모두 이야기문법의 총 수와는 달리 완전한 일화 수를 말하기보다는 쓰기과제에서 더 많이 산출하였다. 완전한 일 화 수에 대한 분산분석 결과, 집단과는 달리 산출 방식에 따라서는 유의미한 차이가 나타나지 않았다. 즉, 말하기와는 달리 쓰기 과제 에서는 두 집단 모두 이야기문법 총 수는 줄어들었지만 이야기의 주요 구성 요소들을 생략하지는 않았던 것이다. 또한 집단과 과제 간에 상호작용 효과가 나타나지 않았으므로, 고기능 ASD 집단 아 동들이 저학년 동안은 일반 아동과 비교적 유사한 수준의 완전한 일화 쓰기가 가능함을 가정할 수 있었다. 이는 말하기와 달리 쓰기 에서 고기능 ASD 아동들 역시 쓰기 내용에 대한 계획이 어느 정도 가능했던 결과로 해석할 수도 있지만, 배경이나 내적 반응에 비해 계기사건이나 시도, 결과와 같은 완전한 일화의 구성요소들의 특이 성이 서술에 영향을 미친 결과로도 보인다. 또한 일반 아동과 비교 해 고기능 ASD 아동들이(1학년 7명, 2학년 1명, 3학년 7명) 일반 아 동(1학년 5명, 2학년 8명, 3학년 2명)과 비교해 학년이 비교적 높았 던 점도 이러한 결과에 영향을 미쳤던 것으로 보인다.

둘째, 담화적 결속장치 사용 수에서 고기능 ASD 아동은 일반 아
동보다 유의미하게 수행이 저조하였으며, 두 집단 모두 쓰기보다는 말하기에서 수행이 유의미하게 높았다. 선행 연구들 역시 고기능 $\mathrm{ASD}$ 집단은 단문 위주로 이야기를 산출하고, 부적절하게 반복된 어휘를 사용함으로 어휘적 결속력을 높이지 못하는 등 담화적 결 속장치 사용에 어려움을 보인다고 보고하였으며 이러한 특성은 학 습 부진 아동들에게서도 발견되고 있다(Baixauli et al., 2016; Choi et al., 2013; Hayes, Norris, \& Flaitz, 1998). 또한 말하기에 비하여 쓰 기는 자신의 생각이나 의도에 대해 문자 체계로 변환하는 처리 과 정을 거쳐 산출해야 하므로, 계획 단계와 더불어 고도의 추상성과 정교화 능력, 의식적인 성찰과 자기 통제 능력까지 요구하는 과제이 므로(Singer \& Bashir, 1999), 쓰기에서 두 집단 모두 담화적 결속장 치 사용이 적었던 것으로 해석할 수 있을 것이다.

본 연구에서 고기능 $\mathrm{ASD}$ 아동들은 이야기를 쓰는 과정에서 단 문 위주의 쓰기 특성에 더해 연결어미와 접속 부사 사용에 제한이 있었다. 이와 더불어, 일반 아동과는 다른 글쓰기 습관을 보였는데, 6 명의 아동이 장면마다 번호를 매겨가며 이야기를 산출하는 것으 로 보아 학교 교과 학습의 영향에 의해 쓰기 기술의 기법을 적용하 고는 있지만, 행동과 사건을 순서적이고 논리적으로 전개하기 위한 이야기 쓰기로써의 연대기적(chronological) 특성을 적용하는 데 는 어려움이 있었다. 또한, 일반 아동 역시 저학년임을 고려할 때, 고 기능 ASD 집단과 마찬가지로 말하기보다 쓰기에서 담화적 결속장 치를 적절하게 사용하는 데는 비교적 어려움이 있었음을 확인할 수 있었다. 고기능 ASD 아동이 보이는 담화적 결속장치 사용의 어 려움은 일차적으로 이들의 화용 결함에서 기인하겠지만 작업기억 을 포함한 집행기능, 마음이론과의 관련성도 논의할 필요가 있을 것이다.

$\mathrm{ASD}$ 아동의 이야기 산출 능력에는 이야기의 유형뿐 아니라 마 음이론이 영향을 미치며, 마음이론은 이들의 이야기 능력에 대한 중요한 예측치로 기능한다고 알려져 있기도 하다(Hilvert et al., 2016). 실제로 마음이론은 사건의 도식 표상에 중요한 역할을 하게 되므 로 마음이론 과제 수행력이 높은 ASD 아동은 이야기문법을 보다 잘 표현할 수 있었으며(Fisher, Happé, \& Dunn, 2005), 주인공의 심 적 상태를 나타내는 빈도가 더 높았다고 한다(Capps, Losh, \& Thurb$\mathrm{er}, 2000)$. 이러한 결과는 고기능 ASD에게서는 더욱 두드러지는데, 설명문 구성력과 응집성이 이들의 마음이론 능력과 상관이 있었다 (Brown \& Klein, 2011). 특히, 고기능 자폐범주성장애 아동은 말하 기에서도 담화적 결속 장치를 적게 사용함으로써 인과 관계를 드 러내거나 대명사의 참조 연결에 어려움을 겪는 것으로 나타났으며 이는 담화 이해와 마음이론을 포함한 화용 능력의 결함에 직접적 인 영향을 주는 요인으로 다뤄지고 있다(Baixauli et al., 2016). 
마지막으로, 총 C-unit 수를 비교한 결과에서는 집단 간 유의미 한 차이는 나타나지 않았으나 평균낱말길이(MLC-w)와 다른 낱말 수(NDW)에서는 집단 간 유의미한 차이가 나타났다. 이는 고기능 $\mathrm{ASD}$ 아동이 의사소통 단위로 이야기를 산출할 수는 있지만 이야 기를 길게 산출하지 않고 간단하고 간결하게 표현했음을 의미한다. 이러한 결과는 선행연구들의 결과와 비슷한 양상이었다(Kwon, 2010; Lee, 2013; Losh \& Capps, 2003). 이와 더불어, 총 C-unit 수에 서는 산출 방식에서도 유의미한 차이가 나타났는데, 두 집단 모두 말하기보다 쓰기에서 수행이 저조하였다. 하지만, 평균낱말길이에 서는 말하기와 쓰기 간에 유의미한 차이가 나타나지 않았다. 이는 이야기 발화의 전체 길이는 쓰기보다 말하기가 길었지만 전체 이야 기의 산출 길이는 말하기와 쓰기가 비슷하다는 의미이다. Kamhi 와 Catts (2011) 역시, 말하기와는 달리 쓰기에서는 불필요한 낱말 사용이 감소하고, 보다 정돈된 문법적 구조를 사용하게 된다고 언 급하고 있다.

C-unit 수에 따른 다른 낱말 수를 분석한 결과, 고기능 ASD 아 동은 일반 아동보다 다른 낱말 수 산출이 적었으며, 두 집단 모두 말하기보다는 쓰기 과제에서 다른 낱말 수를 더 적게 사용하고 있 었다. 이러한 결과는 말하기와 쓰기에서 어휘 다양도와 어휘 밀도 의 유의미한 차이를 발견할 수 있었다는 Kamhi와 Catts (2011)의 제안을 뒷받침한다. 특히, 본 연구에서 고기능 $\mathrm{ASD}$ 아동들은 이야 기를 산출할 때, 등장인물의 이름을 반복하거나 특정 사물을 반복 해서 산출하는 등 제한되고 반복된 어휘를 사용하는 경향이 나타 났다. 이러한 특징은 여러 선행연구들에서도 확인된 바 있다(Kim \& Kim, 2002; Kwon, 2010; Thurber \& Tager-Flusberg, 1993). 특히, 상황에 적절한 어휘 선택이나 대명사사용의 어려움과 관련해 Thurber와 Tager-Flusberg (1993)는 ASD 아동의 사회-인지 결함의 영향 으로 설명하기도 하였다. 하지만, 이러한 특징들이 설명담화나 이 야기, 대화라는 내러티브 형식에 따라 달리 반영되는지에 대해서는 좀 더 논의가 필요할 것으로 보인다.

요약하자면, 학령기 고기능 ASD 아동은 일반 아동과 비교해 이 야기를 말할 때 이야기문법 총 수, 완전한 일화 수, 담화결속장치 사용 수, C-unit 내 평균낱말길이, 다른 낱말 수에서는 수행력이 낮 았다. 하지만, C-unit 총 수에서는 차이가 없었으므로 이들의 이야 기 말하기 분석에서는 이야기의 구성력과 전체 이야기 산출 길이 를 살펴볼 필요가 있음을 확인할 수 있었다. 또한 쓰기 과제에서는 특히 이야기의 완전한 일화 수에서 일반 아동과 차이가 없었으므 로, 초등 저학년 시기의 쓰기 과정에서 이야기의 주요 정보를 전달 할 수 있는 형식에 대한 습득이 가능함을 조심스레 가정할 수 있었 다. 하지만, 내용 면에서는 여전히 다른 낱말 수나 담화결속장치 총
사용 수, 이야기 산출 길이 등에서는 수행이 저조하므로 이러한 특 성이 평가와 중재에 고려되어야 할 것이다.

지금까지 학령기 ASD 아동의 언어중재 시 쓰기는 말하기와 비 교해 연구와 임상 현장 모두에서 거의 다뤄지지 않았던 주제로 보 인다. 하지만, 본 연구에서 살펴본 바와 같이 이야기 구성력과 의미, 구문 모두에서 $\mathrm{ASD}$ 아동들만의 두드러진 쓰기 특성이 있음을 확 인할 수 있었다. 따라서 Kamhi와 Catts (2011)가 지적하듯이 쓰기 결함은 명백하게 그 차이가 드러나기보다는 정도의 문제일 수 있으 므로 이들 아동들의 쓰기 특성에 대한 논의를 좀 더 발전시켜갈 필 요가 있을 것이다.

하지만 본 연구에서는 이야기를 얼마나 길게 말하고 썼는지를 C-unit 내 평균낱말길이만으로 확인하였다는 제한점이 있다. 고기 능 ASD 아동이 일반 아동과 C-unit 수 표현에서 큰 차이가 없었으 므로, C-unit 내에서 이들이 얼마나 많은 단어를 사용했는지와 더 불어, 절(clause) 단위의 구문복잡성을 질적인 심층 분석을 통해 말 하기와 쓰기 특성 모두에서 살펴볼 필요가 있을 것으로 보인다. 또 한 설명글과 같은 다른 다양한 내러티브 형식에서 말하기와 쓰기 간 특성의 차이를 살펴보는 것도 학령기 ASD 아동의 언어 및 학업 수행 촉진을 위한 지원 자료로써 의미가 있을 것이다. 본 연구에서 는 이야기구성력 분석에서 이야기 흐름과 상관없는 발화나 들려준 내용과 다른 이야기를 하는 경우는 결과에 영향을 미치는 수준이 아니었으므로 분석에서 제외하였다. 또한 어휘나 문법, 구문 및 철 자 오류 등을 분석에서 제외하였으나, 학령기 초기 고기능 ASD 아 동에게서 이러한 측정치는 매우 의미 있게 해석되어야 하므로 추후 연구에서는 보다 구체적인 측정치로 다뤄질 필요가 있을 것이다.

연구 방법과 관련하여 본 연구에서는 수용어휘력이 유사한 수 준에서의 집단 간 비교를 위해 수용어휘력검사 점수를 일대일 대 응하여 대상자를 선정하였으므로, 고기능 ASD 집단의 연령과 학 년이 대체로 높은 편이었다. 하지만 담화뿐 아니라 문법과 쓰기 측 면에서도 학년이 올라감에 따라 교과와 학습의 영향 등으로 이들 의 이야기 산출에 많은 변화가 있을 것으로 추후 연구에서는 대상 자 선정에 이러한 점들이 고려되어야 할 것으로 보인다.

\section{REFERENCES}

Ahn, E. J., \& Kim, J. M. (2010). The expository writing abilities of school-aged children. Korean Journal of Communication Disorders, 15, 321-336.

American Psychiatric Association. (2000). Diagnostic and statistical manual of mental disorders, fourth edition, text revision (DSM-IV-TR). Washington, DC: Author. 
American Psychiatric Association. (2013). Diagnostic and statistical manual of mental disorders, fifth edition (DSM-5). Washington, DC: Author.

Baixauli, I., Colomer, C., Roselló, B., \& Miranda, A. (2016). Narratives of children with high-functioning autism spectrum disorder: a meta-analysis. Research in Developmental Disabilities, 59, 234-254.

Barnes, J. L., \& Baron-Cohen, S. (2012). The big picture: storytelling ability in adults with autism spectrum conditions. Journal of Autism and Developmental Disorders, 42, 1557-1565.

Brown, H. M. (2013). Academic achievement of children and adolescents with high-functioning autism spectrum disorder with in-depth focus on written expression (Doctoral dissertation). The University of Western Ontario, Canada.

Brown, H. M., \& Klein, P. D. (2011). Writing, Asperger syndrome and theory of mind. Journal of autism and developmental disorders, 41, 1464-1474.

Capps, L., Losh, M., \& Thurber, C. (2000). “The frog ate the bug and made his mouth sad": narrative competence in children with autism. Journal of Abnormal Child Psychology, 28, 193-204.

Choi, S. Y., Kim, Y. T., \& Yun, S. (2013). Written story coherence of high-functioning autistic children under two narrative presentation condition. Journal of the Korean Association for Persons with Autism, 13, 15-39.

Colle, L., Baron-Cohen, S., Wheelwright, S., \& van der Lely, H. K. (2008). Narrative discourse in adults with high-functioning autism or Asperger syndrome. Journal of Autism and Developmental Disorders, 38, 28-40.

Diehl, J. J., Bennetto, L., \& Young, E. C. (2006). Story recall and narrative coherence of high-functioning children with autism spectrum disorders. Journal of Abnormal Child Psychology, 34, 83-98.

Fisher, N., Happé, F., \& Dunn, J. (2005). The relationship between vocabulary, grammar, and false belief task performance in children with autistic spectrum disorders and children with moderate learning difficulties. Journal of Child Psychology and Psychiatry, 46, 409-419.

Foley-Nicpon, M., Assouline, S. G., \& Stinson, R. D. (2012). Cognitive and academic distinctions between gifted students with autism and Asperger syndrome. Gifted Child Quarterly, 56, 77-89.

Hayes, P. A., Norris, J., \& Flaitz, J. R. (1998). A comparison of the oral narrative abilities of underachieving and high-achieving gifted adolescents: a preliminary investigation. Language, Speech, and Hearing Services in Schools, 29, 158-171.

Heilmann, J., Miller, J. F., Nockerts, A., \& Dunaway, C. (2010). Properties of the narrative scoring scheme using narrative retells in young school-age children. American Journal of Speech-Language Pathology, 19, 154-166.
Heo, H., Kwag, K. M., \& Lee, Y. (2011). The relationship among the reading and writing abilities and oral language skills of school-aged low-achievers in language learning. Korean Journal of Communication Disorders, 16, 2333.

Hilvert, E., Davidson, D., \& Gámez, P. B. (2016). Examination of script and non-script based narrative retellings in children with autism spectrum disorders. Research in Autism Spectrum Disorders, 29, 79-92.

Howlin, P. (2003). Outcome in high-functioning adults with autism with and without early language delays: implications for the differentiation between autism and Asperger syndrome. Journal of Autism and Developmental Disorders, 33, 3-13.

Howlin, P., Goode, S., Hutton, J., \& Rutter, M. (2004). Adult outcome for children with autism. Journal of Child Psychology and Psychiatry, 45, 212-229.

Kamhi, A. G., \& Catts, H. W. (2011). Language and reading disabilities (3rd ed.). Boston, MA: Allyn \& Bacon.

Kim, J. E., \& Kim, Y. T. (2002). Lexical diversity of high-functioning autistic children. Korean Journal of Communication Disorders, 7, 13-29.

Kim, J. M. (2015). Literate language characteristics in expository writing of school-aged children. Journal of Speech \& Hearing Disorders, 24, 29-38.

Kim, T. R., \& Park, R. G. (1996). Childhood autism rating scale (CARS). Seoul: Seoul Special Education Publishing.

Kim, Y. T., Hong, G. H., Kim, K. H., Jang, H. S., \& Lee, J. Y. (2009). Receptive and expressive vocabulary test (REVT). Seoul: Seoul Community Rehabilitation Center.

King, D., Dockrell, J., \& Stuart, M. (2014). Constructing fictional stories: a study of story narratives by children with autistic spectrum disorder. Research in Developmental Disabilities, 35, 2438-2449.

Kwon, E. (2006). Narrative discourse ability for school-aged Asperger's syndrome children in a story-retelling task: story composition, cohesive device and clause (Master's thesis). Hallym University, Chuncheon, Korea.

Kwon, E. (2010). The ability to use syntax in school-aged Asperger's syndrome children in a story-retelling task. Korean Journal of Communication Disorders, 15, 193-204.

Kwon, E., \& Pae, S. Y. (2006). Three measures of narrative discourse ability for Korean school-aged children in a story retelling task. Korean Journal of Communication Disorders, 11, 72-89.

Kwon, E., Pae, S., \& Jin, Y. S. (2009). Korean Narrative Assessment (KONA). Chuncheon: Hallym University.

Landa, R. (2000). Social language use in Asperger syndrome and high-functioning autism. In A. Klin et al. (Eds.), Asperger syndrome (pp. 125-155). 
Hyun Jun Cho, et al. • Story Production Ability of School-aged Children with High-functioning ASD

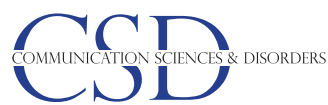

New York, NY: The Guilford Press.

Landa, R. J., \& Goldberg, M. C. (2005). Language, social, and executive functions in high functioning autism: a continuum of performance. Journal of Autism and Developmental Disorders, 35, 557-573.

Lee, B. W. (2015). Korean grammar. Seoul: Hakjisa

Lee, H. N. (2013). Story-retelling performance for children with high-functioning autism via intelligent robot (Master's thesis). Ewha Womans University, Seoul, Korea.

Lee, H. Y., \& Jung, K. H. (2013). Development of spoken and written expository discourse in school-aged children. Journal of Speech \& Hearing Disorders, 22, 145-161.

Losh, M., \& Capps, L. (2003). Narrative ability in high-functioning children with autism or Asperger's syndrome. Journal of Autism and Developmental Disorders, 33, 239-251.

Mäkinen, L., Loukusa, S., Leinonen, E., Moilanen, I., Ebeling, H., \& Kunnari, S. (2014). Characteristics of narrative language in autism spectrum disorder: evidence from the Finnish. Research in Autism Spectrum Disorders, 8, 987-996.

Mayer, M. (1969). Frog, where are you? New York, NY: Dial Press.

Mayes, S. D., \& Calhoun, S. L. (2003). Ability profiles in children with autism: influence of age and IQ. Autism, 7, 65-80.

Mayes, S. D., \& Calhoun, S. L. (2008). WISC-IV and WIAT-II profiles in children with high-functioning autism. Journal of Autism and Developmental Disorders, 38, 428-439.

McCabe, A., Hillier, A., \& Shapiro, C. (2013). Brief report: Structure of personal narratives of adults with autism spectrum disorder. Journal of Autism and Developmental Disorders, 43, 733-738.

Moon, S. B., \& Byun, C. J. (2009). Korean Kaufman assessment battery for children $(K-A B C)$. Seoul: Hakjisa.

Norbury, C. F., \& Bishop, D. V. (2003). Narrative skills of children with communication impairments. International Journal of Language \& Communication Disorders, 38, 287-313.

Norbury, C. F., Gemmell, T., \& Paul, R. (2014). Pragmatics abilities in narrative production: a cross-disorder comparison. Journal of Child Language, 41, 485-510.

Owens, R. E. (2014). Language development: an introduction (8th ed.) Bos- ton, MA: Pearson.

Pae, S., \& Lee, S. H. (1996). A study on the story production of Korean children. Korean Journal of Communication Disorders, 1, 34-67.

Pae, S., Lim, S. S., \& Lee, J. (2000). Test of problem solving (TOPS). Seoul: Seoul Community Rehabilitation Center.

Renner, P., Klinger, L. G., \& Klinger, M. R. (2000). Implicit and explicit memory in autism: is autism an amnesic disorder? Journal of Autism and Developmental Disorders, 30, 3-14.

Scott, C. M. (1999). Learning to write. In H. W. Catts \& A. G. Kamhi (Eds.), Language and reading disabilities (pp. 224-258). Boston, MA: Allyn \& Bacon.

Singer, B. D., \& Bashir, A. S. (1999). What are executive functions and selfregulation and what do they have to do with language-learning disorders? Language, Speech, and Hearing Services in Schools, 30, 265-273.

Stein, N. L., \& Glenn, C. G. (1979). An analysis of story comprehension in elementary school children. In R. O, Freedle (Ed.), New directions in discourse processing. Norwood, NJ: Ablex Publishing Corp.

Strömqvist, S., Nordqvist, Å., \& Wengelin, Å. (2004). Writing the frog-story: developmental and cross-modal perspectives. In S. Strömqvist \& L. Verhoeven (Eds.), Relating events in narrative: typological and contextual perspectives (pp. 359-394). Hillsdale, NJ: Lawrence Erlbaum Associates.

Tager-Flusberg, H. (2000). Understanding the language and communicative impairments in autism. International Review of Research in Mental Retardation, 23, 185-205.

Tager-Flusberg, H. (2004). Strategies for conducting research on language in autism. Journal of Autism and Developmental Disorders, 34, 75-80.

Tager-Flusberg, H., Paul, R., \& Lord, C. (1997). Language and communication in autism. In D. J. Cohen \& F. R. Volkmar (Eds.), Handbook of autism and pervasive developmental disorders (pp. 195-225). New York, NY: John Wiley \& Son.

Thurber, C., \& Tager-Flusberg, H. (1993). Pauses in the narratives produced by autistic, mentally retarded, and normal children as an index of cognitive demand. Journal of Autism and Developmental disorders, 23, 309-322.

Youn, J. J., Kim, Y. S., \& Ham, E, S. (2007). The relationship between the story-telling and story-writing of children. Journal of Korea Open Association for Early Childhood Education, 12, 207-225. 
Appendix 1. 담화적 결속장치의 유형별 조작적 정의

연결어미 어말어미의 한 갈래로서 용언 뒤에 붙어 한 문장을 끝맺지 않고 용언과 뒤에 오는 단어, 단어결합 혹은 문장의 부분과 부분을 여러 가지 관계로 연결하 여 주는 어말어미이다. 본 연구에서는 다음 세 가지 연결어미를 분서에 포함시켰다.

1. '-고, -며, -면서' 등과 같이 뒤에 오는 문장을 대등한 자격으로 이어주는 기능을 하는 대등적 연결어미.

2. '면, -니, -는데, -니까' 등과 같이 앞의 문장을 뒷 문장에 종속적인 관계로서 이어주는 기능을 하는 종속적 연결어미.

3.-아/어/여, -고, -게, -지' 와 같이 보조적 용언을 본용언에 이어주는 기능을 하는 보조적 연결어미.

4. “좋아(서) 죽겠어."처럼 연결어미가 생략된 경우는 화자의 정확한 의도를 알 수 없기 때문에 포함하지 않았다.

접속사 접속사는 '그래서, 그러나'와 같이 완결되지 못한 문장과 문장이나, 완결된 문장과 문장을 접속시키는 역할을 한다. 접속사는 나열, 계기, 대립, 상황, 인과, 전환, 목적, 동시 등의 접속 상황을 나타낸다.

지시 및 대용 선행 또는 후행 문장에서 언급되는 사물, 사람, 사건 등의 실체를 지시라 하고 청자와 화자가 공유하고 있다고 여겨지는 정보를 지시하되 공유정보의 자리에 다른 낱말을 대신 사용하는 것을 대용이라 한다.

1. 지시적 표현 ‘이, 그, 저’와 대용적 표현 ‘나, 자신' 등으로 그 자체로는 실제적 의미를 지니지 않고 다른 표현에 대신하여 사용되는 것을 포함하였다. 2. 부정칭대명사, 한정부사어, 인칭대명사, 재귀대명사를 포함하였다.

보조사 체언, 부사, 활용 어미 등에 결합해서 특별한 의미를 더하는 보조사는 문법적 관계를 나타내지는 않고 특별한 의미를 덧붙여 준다. : 보조사 ‘-도, -만, -까지, -부터, -밖에’ 등을 사용하는 경우.

어휘결속을 높이는 어휘를 새롭게 첨가하거나 앞의 명제를 연결하는 유사 어휘를 사용하는 결속장치이다. : ‘더욱더/더/더욱, 자꾸/계속, 다음, 또, 다시, 아무리, 나머지, 함께, 갑자기’ 등 어휘

출처: Kwon (2006), Choi, Kim, \& Yun (2013). 


\title{
국문초록
}

\author{
학령기 고기능 자폐범주성장애 아동의 이야기 말하기와 쓰기 특성 \\ 조현준 ${ }^{1} \cdot$ 이희란 $^{2}$ \\ 1좋은강안병원, ${ }^{2}$ 부산가톨릭대학교 언어청각치료학과
}

배경 및 목적: 본 연구에서는 초등학교에 재학 중인 고기능 $\mathrm{ASD}$ 아동을 대상으로 말하기와 쓰기에 따른 이야기 산출 능력을 살펴봄으 로써, 이들의 언어 및 담화 특성을 파악하고자 하였다. 방법: 대상자는 초등학교 저학년(1-3학년) 고기능 ASD 아동 15명, 그리고 이들과 수용 이해력을 일치시킨 일반 아동 15 명으로 총 30 명이었으며, 이야기 말하기와 쓰기 과제를 통해 이야기 구성력과 담화적 결속장치, 서로 다른 낱말 수(NDW), C-unit 내 평균낱말길이(MLC-w)를 분석하였다. 결과: 연구 결과, 첫째, 학령기 고기능 ASD 아동은 말하기 와 쓰기 과제 모두에서 이야기문법 총 수, 담화적 결속장치 총 사용 수, 평균낱말길이, 서로 다른 낱말 수 산출이 일반 아동보다 유의미 하게 수행이 저조하였지만, 총 C-unit 수에서는 두 집단 간에 유의미한 차이가 나타나지 않았다. 둘째, 두 집단 모두 쓰기보다 말하기에 서 유의미하게 높은 수행력을 보였지만, 평균낱말길이와 완전한 일화 수에서는 산출 방식 간에 유의미한 차이가 나타나지 않았다. 논의 및 결론: 본 연구에서는 고기능 ASD 아동의 이야기 산출 능력이 어휘 이해력이 유사한 수준의 일반 아동과 비교해, 구문의 길이에서는 차이가 없었지만 평균낱말길이와 다른 낱말 수(NDW) 사용에서는 어려움이 있음을 확인할 수 있었다. 또한 이야기 말하기와 쓰기의 산출 방식 간에도 유의미한 차이가 있어 학령기 고기능 $\mathrm{ASD}$ 아동에게 이야기과제 평가 시 말하기뿐만 아니라 쓰기까지 고려하여 이야 기 산출 능력을 파악하는 것이 필요함을 논의하였다.

핵심어: 고기능 자폐범주성장애, 이야기, 학령기, 말하기, 쓰기

본 논문은 제 1 저자의 석사학위논문을 수정 보완하였음.

\section{참고문헌}

권유진(2006). 초등 저학년 아스퍼거증후군 아동의 이야기 회상 산출 능력: 이야기 구성 결속표지, 구문표현. 한림대학교 박사학위논문.

권유진(2010). 초등 저학년 아스퍼거증후군 아동의 구문 표현 능력. 언어청각장애연구, 15, 193-204.

권유진, 배소영(2006). 이야기 다시말하기(story retelling) 과제를 통한 초등 저학년 아동의 이야기능력. 언어청각장애연구, 11, 72-89.

권유진, 배소영, 진연선(2009). 이야기 평가(KONA). 춘천: 한림대학교 언어청각학부.

김영태, 홍경훈, 김경희, 장혜성, 이주연(2009). 수용·표현어휘력검사(REVT). 서울: 서울장애인종합복지관.

김정미(2015). 학령기 일반아동의 설명담화 쓰기자료에 나타난 문어적 특성. 언어치료연구, 24, 29-38.

김지은, 김영태(2002). 이야기 산출과제를 이용한 고기능 자폐아동과 정상아동의 어휘다양도 비교연구. 언어청각장애연구, 7, 13-29.

김태련, 박랑규(1996). 아동기자폐증평정척도(CARS). 서울: 도서출판 특수교육.

문수백, 변창진(2009). K-ABC 교육·심리측정도구(Korean-Kaufman assessment battery for children). 서울: 학지사.

배소영, 이승환(1996). 한국 아동의 이야기 산출 연구. 말-언어장애연구, 1,34-67.

배소영, 임선숙, 이지희(2000). 언어문제해결력검사. 서울: 서울장애인종합복지관.

안은주, 김정미(2010). 초등학교 2, 4,6학년 아동의 설명담화 쓰기 비교. 언어청각장애연구, 15, 321-336.

윤진주, 김영실, 함은숙(2007). 유아의 이야기 말하기 능력과 이야기 쓰기 능력 간의 관계. 열린유아교육연구, 12, 207-225.

이봉원(2015). (언어치료사를 위한) 한국어문법. 서울: 학지사.

이하나(2013). 지능형 로봇을 활용한 고기능자폐아동의 이야기 다시 말하기 양상 분석. 이화여자대학교 석사학위논문.

이혜연, 정경희(2013). 학령기 아동의 설명담화 말하기와 쓰기 발달: 구문, 의미, 결속장치를 중심으로. 언어치료연구, 22, 145-161.

최소영, 김영태, 윤선아(2013). 이야기 제시 조건에 따른 초등학교 저학년 고기능 자폐 아동들의 쓰기 응집력 특징. 자폐성장애연구, 13, 15-39.

허현숙, 곽경미, 이윤경(2011). 언어학습부진 아동의 구어능력과 읽기, 쓰기 능력과의 관계. 언어청각장애연구, 16, 23-33. 